\title{
Research on the Development and Preliminary Application of 12396 New Rural Sci-tech Service Hotline WeChat Public Platform
}

\author{
Li Zhimei, Luo Changshou and Zhang Junfeng*
}

\begin{abstract}
Institute of Information on Science and Technology of Agriculture, Beijing Academy of Agriculture and Forestry Sciences, No.9, Shuguang Huayuan Road, Beijing, China
\end{abstract}

\begin{abstract}
Based on the requirement analysis, combined with the characteristics of WeChat and WeChat public platform, we analyzed the feasibility and necessity of WeChat used in agricultural information service, and discussed the mode of WeChat used in agricultural information service. To overcome the limitations existing in Tencent WeChat public platform applied in the agricultural information consulting services, java language was used to do further development based on WeChat open interface, and the micro website was established to realize the information transition from PC website to the mobile web site. WeChat was used to provide agricultural expert consulting services, agriculture information push and self access, and obtained a good preliminary application effect. Finally, the innovation application of WeChat used in agricultural information consulting services and the aspects of WeChat could be expanded in the agricultural information service application were summarized.
\end{abstract}

Keywords: WeChat, Consulting service, 12396 hotline, Agricultural information service.

\section{INTRODUCTION}

The popularity of smart phones and broadband Chinese strategy provide a wide prospect for mobile application service in agriculture. "China Mobile Internet development report (2014)" blue book reported that, by January 2014, there would be 838 million mobile internet users in China, accounted for $67.8 \%$ in the mobile phone users. Mobile phone users reached 500 million, accounted more than eighty percent of the total Internet users. Mobile phones remained the largest Internet terminal, and China Mobile Internet developed into the universal time [1]. According to "The 32nd Statistical Report on Internet Development in China 2013", mobile phone had become the main Internet equipment of rural users, with the utilization rate as high as $78.9 \%$ [2]. In addition, in August 17, 2013 the State Council announced the broadband Chinese strategic implementation plan, to basically realize the rural broadband coverage by 2015 .

WeChat is a free instant messaging service application for intelligent terminals, which Tencent Inc launched in January 21,2011 . WeChat can support cross communication operators and cross operating system platforms. Users can send videos, voices, pictures and texts by the mobile phone, tablet and webpage quickly and free of charge (required to consume a small amount of network traffic). Compared with the traditional communication of mobile phone, Fetion, and micro-blog, WeChat has obvious advantages [3, 4], According to the Tencent official statistics, as of the end of 2013,
WeChat became an instant communication software with the largest mobile user groups in Asia, registered users of which exceeded 600 million [1]. WeChat public platform is a new function module based on WeChat, which Tencent Inc officially launched on August 23, 2012. Through this platform, both individuals and organizations can create a WeChat public account to interact with fans, and obtain the group sending option and the powerful statistical functions. At present, WeChat public platform supports PC users, and uses can bind individual WeChat account to interact with fans by smart phone. On August 5, 2013, WeChat public platform was upgraded to divide the platform into the WeChat public service account and subscription account types. WeChat users can scan the two-dimensional code, search the account number or nickname to become fans of the WeChat public platform accounts, at the same time save and share wonderful messages.

With powerful function and huge user groups, WeChat has been used in many fields of information service by the media, government institutions and enterprises etc. $[5,6]$. In the agricultural information service field, WeChat has also been widely used. Agricultural hotlines mainly provide expert consulting services and send agricultural information through WeChat, such as Beijing 12396, Hunan 12396, Shandong 12396, Inner Mongolia 12396, Putian 12396, Liaoning 12316, Jiangsu 12316, Qinghai 12316, Hunan 12316, Hebei 12316, Xinjiang 12316, Gansu 12316, Chongqing 12316, Wuhan 12316, Qigihar 12316, Liuyang 12316, Lianyungang 12316 and Sanya agriculture Technology 110. Agricultural media WeChat public accounts mainly push the "three rural" related news, such as China Agricultural News and Farmer's Daily. Agriculture related enterprises use WeChat for product promotion, sales and customer consulting service. 

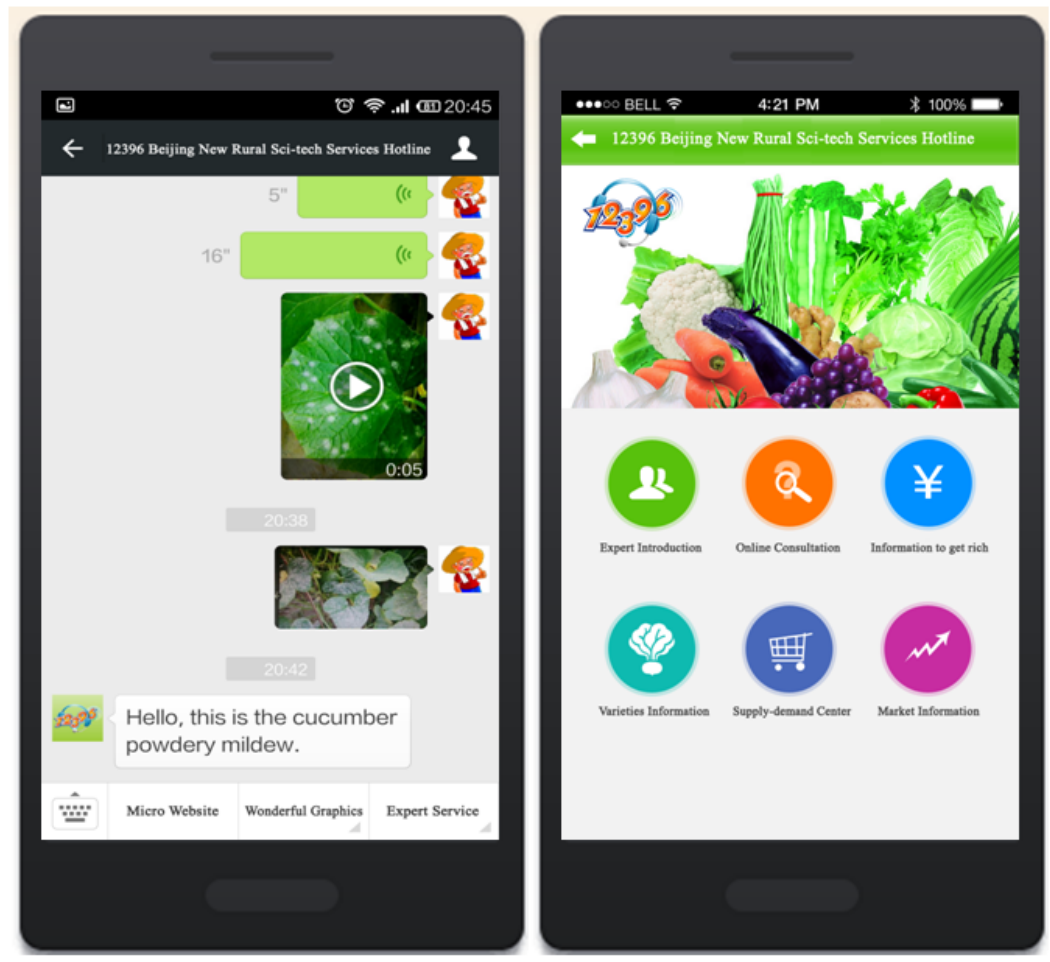

Fig. (1). Interfaces of $12396 \mathrm{WeChat} \mathrm{(left)} \mathrm{and} \mathrm{micro} \mathrm{website} \mathrm{(right).}$

12396 is the rural science and technology information service hotline built by the Ministry of science and technology and the Ministry of information and industry nationwide in China. "12396 Beijing New Rural Technology Services Hotline" is established by the Rural Development Center of Beijing Municipal Science and Technology Commission with Beijing Academy of Agriculture and Forestry Sciences, is a science and technology information service integrated platform for agriculture, and provides agricultural technology information consulting services by more than one hundred experts. Beijing 12396 hotline service has won remarkable results, and needs to expand the service channel and establish service brand as soon as possible. It is particularly urgent and important to combine the modern information technology, give full play to the role of service hotline, and provide scientific and technological information service better for the farmers. WeChat, a new powerful tool of agricultural information mobile service, makes farmers and experts seamlessly integrated on mobile phone. $12396 \mathrm{WeChat}$ platform can broaden the service channels and make the service more convenient, communicate timely and effectively, reduce the cost and accelerate promotion, enhance the brand and upgrade the image, influence the public and enhance the confidence.

\section{SYSTEM DESIGN AND DEVELOPMENT}

Mainly to solve two problems: one is how to use the WeChat to broaden service channels of 12396 hotline, provide more convenient services for agricultural technicians and farmers, and enhance the brand image of the 12396 hotline. The other is how to do further development based on WeChat public platform against the function deficiency of the existing WeChat public platform, to meet the service needs of the 12396 hotline better. The 12396 WeChat public platform was developed and automatic reply data resources were constructed focus on the two problems.

\subsection{Function Design of the 12396 WeChat Public Plat- form}

Combining with the requirements and Tencent WeChat public platform, $12396 \mathrm{WeChat}$ public platform was developed to make it more convenient for customer service staffs and experts to use. Based on the Java platform, "struts+spring+hibernate" framework and jquery were used to realize the asynchronous operation. As the WeChat public platform only can preserve consulting messages for 5 days, the development realized that the consulting messages could be preserved forever and synchronized to the 12396 hotline website online consulting library, and the messages could be searched. As there isn't "non response message list" and users' consulting messages cannot be real-time pop-up in the Tencent WeChat public platform, in order to ensure our experts can see the questions easily and timely, real-time message pop-up or remind and non response message list functions were developed. As a user can only be classified into one group in the Tencent WeChat public platform, but a user may interest in two or more kinds of information, so, to make messages sending by group more precisely, a user can have two or more labels according to the user's consultation in 12396 WeChat public platform. We cannot respond to users 48 hours after user's messages in Tencent WeChat public platform, the development realized that experts could reply to users 48 hours after user's messages, and users could send arbitrary interactive message to get the reply messages in 12396 WeChat public platform. Statistical 


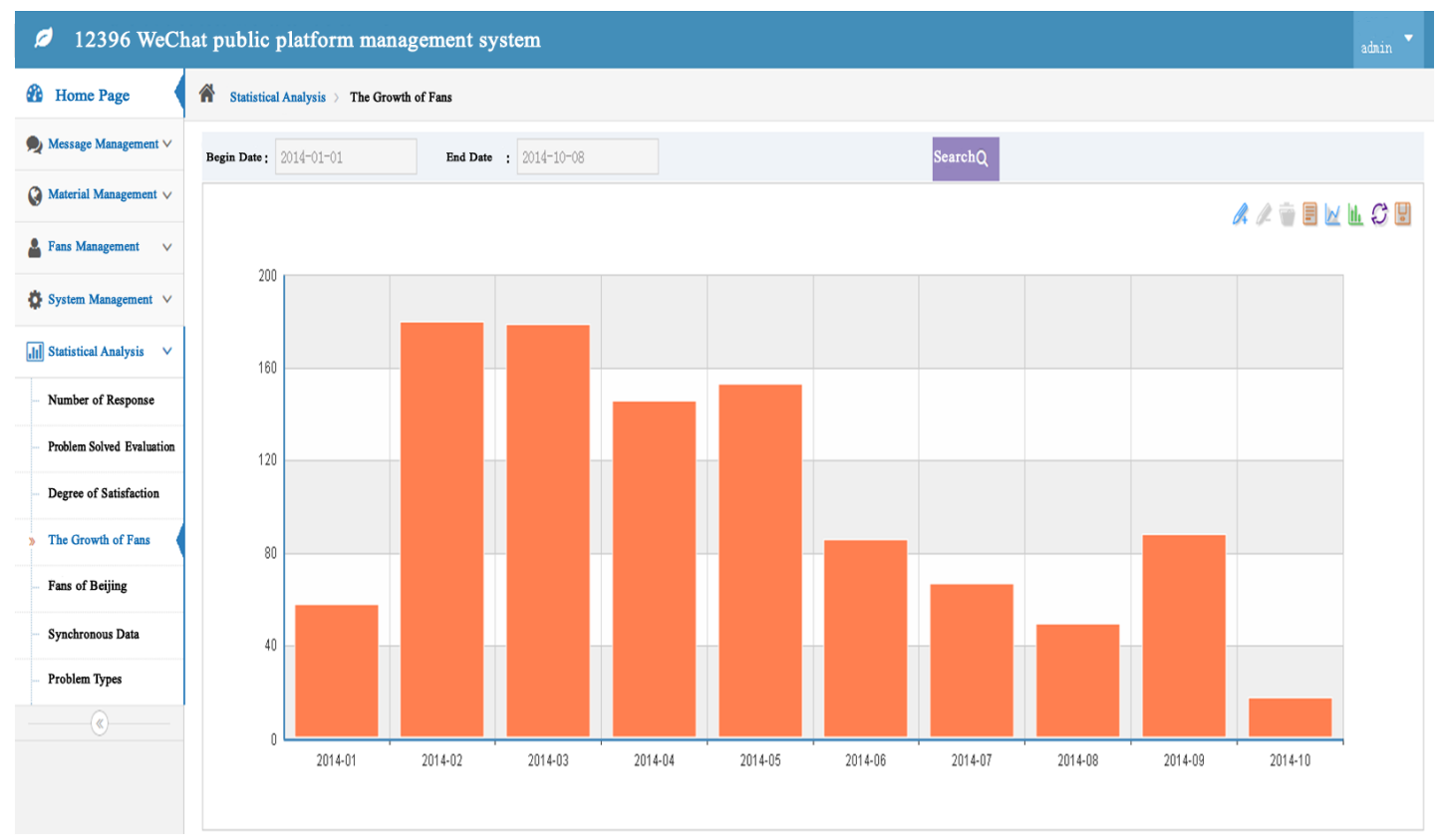

Fig. (2). The management system of $12396 \mathrm{WeChat} \mathrm{public} \mathrm{platform.}$

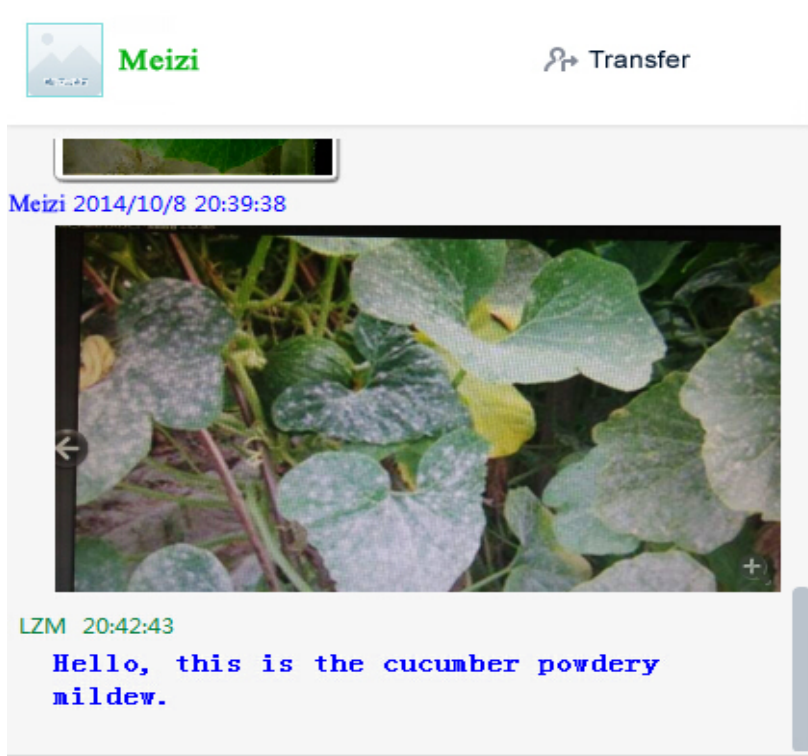

A :) 司
Synchronization Quick Reply

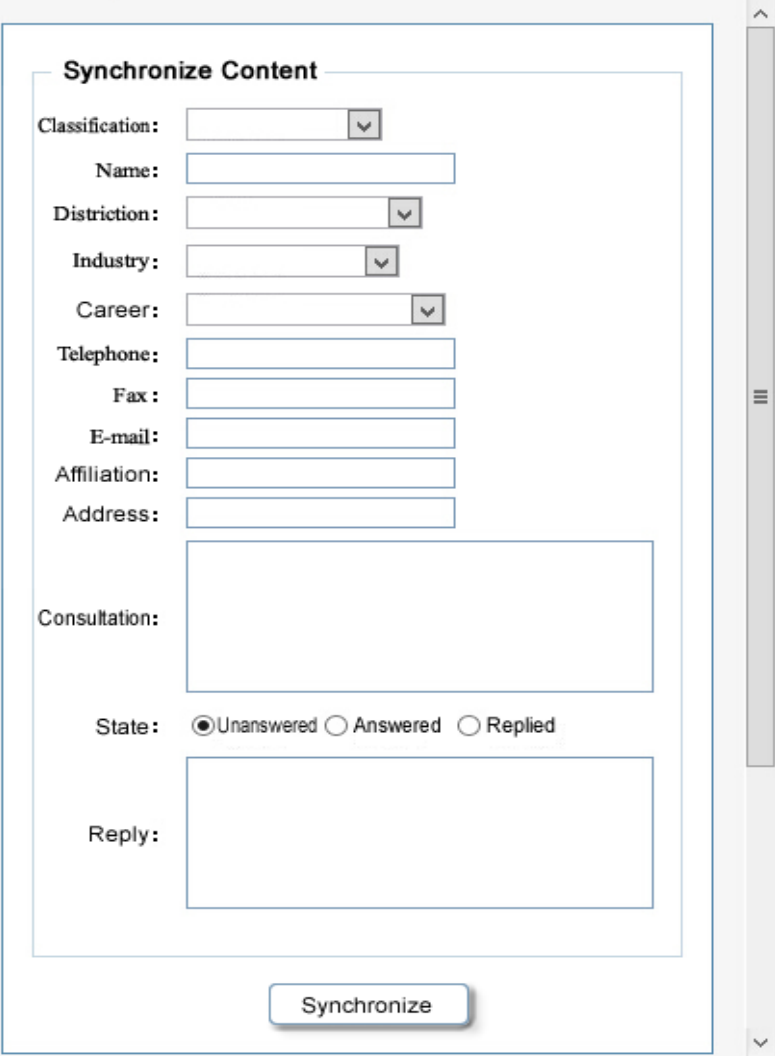

Fig. (3). The information synchronization interface.

functions as well as micro website were developed. Interfaces of 12396 WeChat and micro website are shown in Fig. (1), the management system of 12396 WeChat public platform is shown in Fig. (2), and the information synchronization interface is shown in Fig. (3).

\subsection{The Construction of Automatic Reply Data Re- sources}

Considering the consumption of mobile data flow of voices and videos is larger currently, WeChat public 


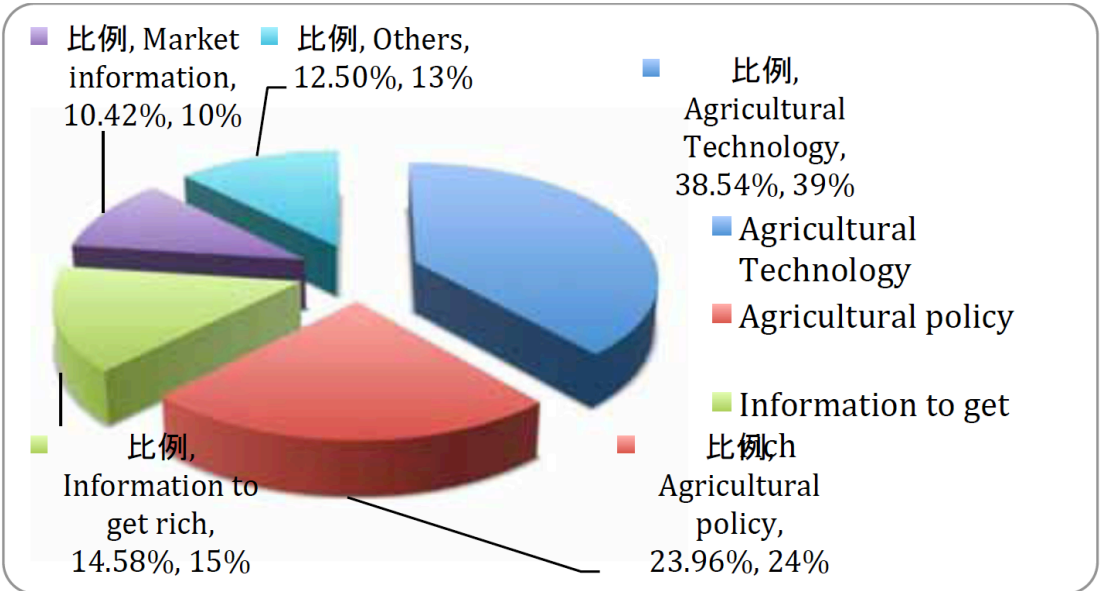

Fig. (4). Categories of user' consulting questions.

platform automatic reply information resources were built with graphics and text information. The classification and digital indexing of information were finished, and the hierarchical automatic reply information was used to guide the user to obtain planting information. For example, according to the automatically reply, user can automatically receive the pest control methods of cucumber by entering "32", "3" means "pest control", "2" means "cucumber".

\section{THE PRELIMINARY EXTENSION}

The promotion model of "online and offline" was used to enhance the brand of 12396 WeChat public platform to bind more loyal users. Online promotion: the two-dimensional code extension of 12396 WeChat public platform was used to get more users and expand the influence through Beijing 12396 websites, micro-blogs, community forums and other ways; Offline promotion: the online users was increased through offline promotion ways such as the 12396 countryside training, 12396 community service and special presentations, science and technology weeks. Preliminary application effect was good. The analysis of users' consultation problem categories is shown in Fig. (4), most users care about agricultural technology and policy, and information to get rich as well as market information also accounts for a certain proportion.

\section{CONCLUSION AND FUTURE DEVELOPMENT}

A convenient agricultural information service mobile application was constructed, the service channel of 12396 hotline was broadened, and 12396 brand popularity was increased by making full use of the 12396 multi-media and expert resources, as well as the super functions of the WeChat public platform. In conclusion, we developed an agricultural information service mode, constructed a kind of agricultural information service model for mobile applications, and provided an effective way for farmers to solve practical problems in agricultural production and management whenever and wherever.
However, development based on the Tencent interfaces must be limited by the Tencent interfaces, resulting in limitations on the implementation of some features, such as pictures, voice and video information size limit, as well as the limitations of the implementation way of graphic material editing and menu settings. We need a more open platform to provide more powerful interface function, at the same time, the development ability of our developers need to be promoted further.

Looking forward to the future, combine the WeChat voice recognition function with the consulting database, use the intelligent breaking word matching technology to realize the voice consultation auto reply function. With the WeChat store we can display and sale new agricultural varieties, products and technologies. We can make the scientific research information acquisition and use more convenient, and promote scientific research achievements into practical application by using the social sharing function of the WeChat.

\section{CONFLICT OF INTEREST}

The author confirms that this article content has no conflict of interest.

\section{ACKNOWLEDGEMENTS}

This work was supported by the projects "Beijing City rural distance information service engineering technology research center" and "Innovation and Development Fund of Institute of Information on Science and Technology of Agriculture, Beijing Academy of Agriculture and Forestry Sciences". The authors would like to thank Sun Sufen, Wang Jinjuan, Cao Chengzhong, Wei Qingfeng and Zheng Yaming for their support and help.

\section{REFERENCES}

[1] H. Li, and L. Yang, "China Mobile Internet Development Report 2014", People's Daily, 2014. 
[2] CNNIC. The $32^{\text {nd }}$ Statistical Report on Internet Development in China, 2013.

[3] Baidu encyclopedia. WeChat. http://baike.baidu.com/view/5117297.htm?fr=aladdin, 2014.

[4] Y. Wang, "WeChat and Micro propagation", Media Observer, vol. 2, pp. 39-41, 2013
[5] Tencent University. WeChat Annual Selection. http://daxue.qq.com/wechat/wechat list/cat id/215, 2014.

[6] H.P. Huang, W.H. He, and Q. Ye, "WeChat and its application in library information service", Library Journal, vol. 1, pp. 62-64. 2013.

Received: September 22, 2014

(C) Zhimei et al.; Licensee Bentham Open.

This is an open access article licensed under the terms of the Creative Commons Attribution Non-Commercial License (http://creativecommons.org/licenses/by-nc/3.0/) which permits unrestricted, non-commercial use, distribution and reproduction in any medium, provided the work is properly cited. 